\title{
Peter Piper's pursuit of a perfect, parsimonious predictive model for prolonged air leaks
}

\author{
Ryan A. Macke, MD
}

\author{
From the Department of Surgery, University of Wisconsin School of Medicine and Public Health, Madison, Wis. \\ Disclosures: Author has nothing to disclose with regard to commercial support. \\ Received for publication Oct 24, 2016; accepted for publication Oct 27, 2016; available ahead of print Nov 19, \\ 2016. \\ Address for reprints: Ryan A. Macke, MD, H4/318 Clinical Sciences Center, 600 Highland Ave, Madison, WI \\ 53792 (E-mail: macke@surgery.wisc.edu). \\ J Thorac Cardiovasc Surg 2017;153:688-9 \\ 0022-5223/\$36.00 \\ Copyright (c) 2016 by The American Association for Thoracic Surgery \\ http://dx.doi.org/10.1016/j.jtcvs.2016.10.040
}

Prolonged air leak (PAL) continues to be a common complication after pulmonary resection. ${ }^{1-5}$ Unfortunately, reproducible and cost-effective means of prevention remain elusive, and optimal postoperative management continues to be debated. ${ }^{6}$ Although PALs are associated with increased risk of other pulmonary complications, ${ }^{7}$ most cases are relatively uncomplicated, resolving with simple chest tube drainage and time. This strategy results in patient discomfort and frustration, however, which is often exacerbated by the unpredictable duration of treatment. PALs are also associated with increased cost and resource use resulting from the use of unproven and expensive prophylactic adjuncts, prolonged hospitalization or outpatient management, and additional interventions to address nonhealing PALs and related complications. ${ }^{7}$ As national efforts to improve measures such as patient satisfaction, cost reduction, and quality of care continue to shape the future of health care, we as thoracic surgeons must critically assess our practices to identify high-yield areas for improvement. PAL prevention and management certainly appears to be a justifiable focus for such efforts.

In this issue of the Journal, Attaar and colleagues ${ }^{8}$ describe their development and internal validation of a clinical prediction model for PAL that was based on retrospective review of their single-institution experience of more than 2300 pulmonary resections, with a reported PAL incidence of $8.6 \%$. A rigorous set of analyses was performed with Society of Thoracic Surgeons-defined preoperative and intraoperative variables to identify 10 risk factors, which were then weighted to create a nomogram-scoring system and used to stratify patients into 3 risk groups. Relative to the patients at lowest risk, those with PAL were 12 times more likely to be in the high-risk group and 5 times more likely to be in the intermediate-risk group.

The large study population permitted inclusion of a greater number of variables in their model than were analyzed in previous studies, ${ }^{2-5}$ facilitating identification of previously unreported risk factors and potentially important interaction effects. Low body mass index, ${ }^{3-5}$ low percentage of

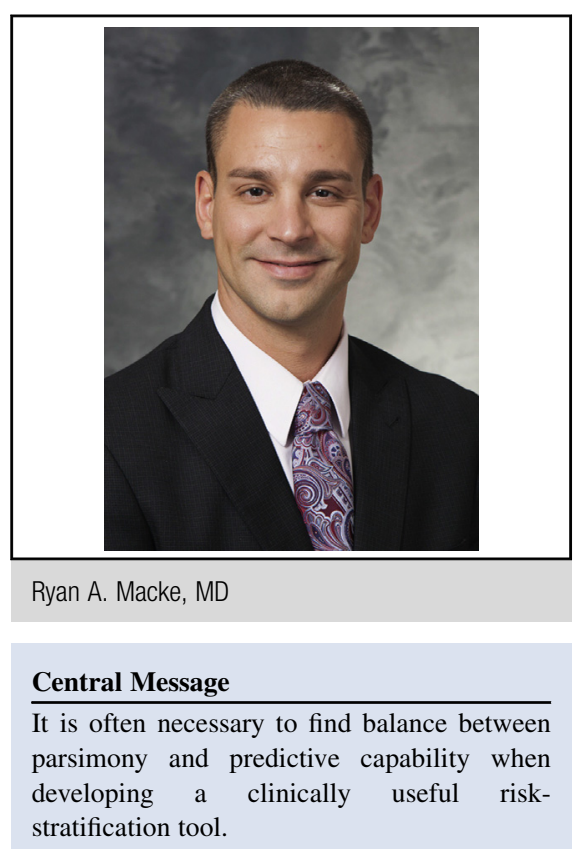

See Article page 690.

predicted forced expiratory volume in 1 second, ${ }^{1,2,4}$ and anatomic resection $^{1,3}$ were once again found to be negative predictors for PAL, and they carry the most weight in the provided nomogram. Other included risk factors that intuitively would seem associated with PAL, such as smoking and reoperation, interestingly have not been previously confirmed. The fact that increasing surgeon volume was associated with risk of PAL was by far the most perplexing finding, because most would expect an inverse relationship. Although Attaar and colleagues ${ }^{8}$ dedicated significant effort, including further analysis, to achieving a better understanding of this association, what becomes most evident on reading is that there are other important factors that remain unaccounted for in their analysis.

It is often necessary to find balance between parsimony and predictive capability when developing a clinically useful risk-stratification tool. A highly predictive model including a large number of variables or complex calculations is less likely to be applied clinically because of missing data or difficulty of use. In contrast, a simple model including only a few widely available clinical variables may be easier to use, but it is likely to suffer in terms of predictive capability.

By using routinely collected Society of Thoracic Surgeons-defined clinical variables, Attaar and colleagues ${ }^{8}$ 
have been able to provide a generalizable model with relatively good accuracy that should be easy to use either retrospectively or prospectively. Some degree of predictive accuracy is lost by omitting potentially relevant clinical variables not collected for the Society of Thoracic Surgeons database, such as presence of pleural adhesions, use of prophylactic adjuncts, specifics of resection type, and method of fissure dissection. Despite this, it appears that Attaar and colleagues ${ }^{8}$ have found solid middle ground between parsimony and predictive capability with their PAL risk model, providing investigators with a useful tool for future study focusing on cost-effective prevention and management of one of the more troublesome complications commonly encountered by thoracic surgeons. ${ }^{8}$

\section{References}

1. Liang S, Ivanovic J, Gilbert S, Maziak DE, Shamji FM, Sundavesan RS, et al. Quantifying the incidence and impact of postoperative prolonged alveolar air leak after pulmonary resection. J Thorac Cardiovasc Surg. 2013:145:948-54.

2. Lee L, Hanley SC, Robineau C, Sirois C, Mulder DS, Ferri LE. Estimating the risk of prolonged air leak after pulmonary resection using a simple scoring system. $J$ Am Coll Surg. 2011;212:1027-32.

3. Rivera C, Bernard A, Falcoz PE, Thomas P, Schmidt A, Bénard S, et al. Characterization and prediction of prolonged air leak after pulmonary resection: a nationwide study setting up the index of prolonged air leak. Ann Thorac Surg. 2011;92: 1062-8; discussion 1068.

4. Brunelli A, Varela G, Refai M, Jimenez MF, Pompili C, Sabbatini A, et al. A scoring system to predict the risk of prolonged air leak after lobectomy. Ann Thorac Surg. 2010;90:204-9.

5. Gilbert S, Maghera S, Seely AJ, Maziak DE, Shamji FM, Sundaresan SR, et al. Identifying patients at risk of prolonged air leak after lung resection. Ann Thorac Surg. 2016;102:1674-9.

6. Belda-Sanchis J, Serra-Mitjans M, Iglesias Sentis M, Rami R. Surgical sealant for preventing air leaks after pulmonary resection in patients with lung cancer. $\mathrm{Co}$ chrane Database Syst Rev. 2010;1:CD003051.

7. Varela G, Jiménez MF, Novoa N, Aranda JL. Estimating hospital costs attributable to prolonged air leak in pulmonary lobectomy. Eur J Cardiothorac Surg. 2005;27: 329-33.

8. Attaar A, Winger DG, Luketich JD, Schuchert MJ, Sarkaria IS, Christie NA, et al. A clinical prediction model for prolonged air leak after pulmonary resection. J Thorac Cardiovasc Surg. 2017;153:690-9. 